\title{
Commentary: Extended left ventricular septal myectomy for hypertrophic cardiomyopathy: The nuts and bolts
}

\author{
Sameh M. Said, MBBCh, MD, FACS
}

\author{
Division of Pediatric Cardiovascular Surgery, Masonic Children's Hospital, University of Minnesota, Minneap- \\ olis, Minn. \\ Disclosures: Dr Said is on the Advisory Board of Admedus. \\ Received for publication Sept 29, 2019; revisions received Sept 29, 2019; accepted for publication Sept 30, 2019; \\ available ahead of print Nov 21, 2019 \\ Address for reprints: Sameh M. Said, MBBCh, MD, FACS, Division of Pediatric Cardiovascular Surgery, \\ Masonic Children's Hospital, University of Minnesota, Minneapolis, MN 55454 (E-mail: ssaid@umn.edu). \\ J Thorac Cardiovasc Surg 2020;159:e299-300 \\ $0022-5223 / \$ 36.00$ \\ Copyright (c) 2019 by The American Association for Thoracic Surgery \\ https://doi.org/10.1016/j.jtcvs.2019.09.146
}

In the current video by Salmasi and colleagues, ${ }^{1}$ the authors demonstrate the technique of left ventricular septal myectomy combined with aortic root replacement in a 56-year-old man with an unusual case of dilated aortic root and hypertrophic cardiomyopathy (HCM). The association between dilated aortic root and HCM is quite rare, but it could be related to the flow turbulence resulting from left ventricular out flow tract obstruction (LVOTO); however, the patient also had an FBN-1 mutation. The authors also plicated the anterior mitral valve (MV) leaflet through the dilated root. While the video is clear and the technique is well-demonstrated, a few technical tips and pitfalls are worth emphasizing:

1. Transaortic left ventricular septal myectomy is the gold standard for patients with hypertrophic obstructive cardiomyopathy, especially for those with the most common variant, the basal variant. ${ }^{2}$

2. The resection has to extend further into the left ventricular cavity - this may not be possible sometimes beyond the body of the anterolateral papillary muscle of the MV. It also depends on other challenging factors, such as the aortic annular size and the patient's body habitus, and in these cases a transapical approach may be required. ${ }^{3}$

3. A proper septal myectomy is a 3-dimensional operation in regards to the extent of resection ${ }^{4}$ : vertical (as further as possible into the left ventricular cavity), horizontal, starting below the nadir of the right coronary cusp, and it goes in an ante-clockwise direction toward the commissure between the right and left coronary cusps and should be widened further down (once we are away from the conduction tissue and the nadirs of the aortic cusps), and finally anteroposterior, which decreases the septal thickness. This 3-dimensional concept guarantees elimination of the LVOT gradient.

4. Although it's important to rule out mitral valvular and subvalvular abnormalities contributing to LVOTO such vers.

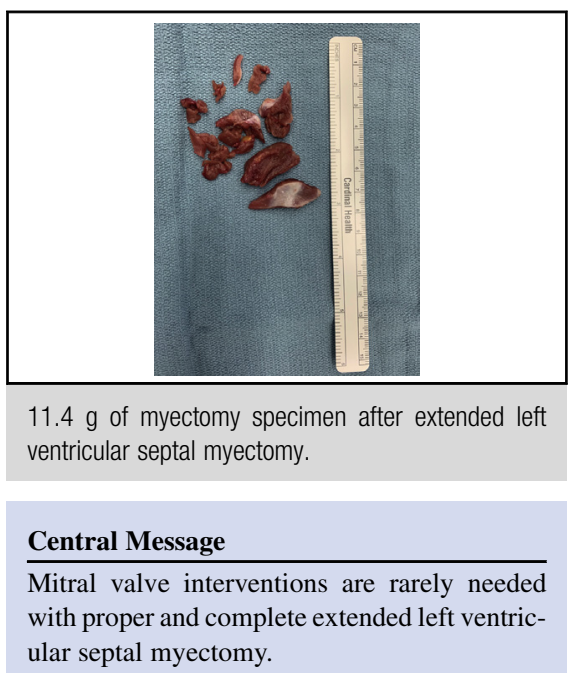

See Article page e295.

as anomalous chordae/papillary muscles that may need to be addressed, there is no need to manipulate the MV or perform maneuvers to the anterior leaflet such as plication due to the following facts:

a. Mitral regurgitation results from the dynamic nature of HCM and it is not related to intrinsic MV abnormalities in the majority of cases.

b. Proper extended left ventricular septal myectomy is associated with complete elimination of the systolic anterior motion of the MV and all mitral regurgitation that is related to the dynamic nature of hypertrophic obstructive cardiomyopathy.

c. Only a small set of patients who had intrinsic MV abnormalities may require MV repair. ${ }^{5}$ In fact, the addition of MV repair or replacement has been associated with increased mortality, as reported recently. ${ }^{6}$

d. We don't have data on the long-term outcomes and competence of the MV as the result of these maneu-

e. It is not clearly known what exactly the degree of plication needed and in which direction.

f. The literature has a mixed set of techniques that have been described in addressing the MV, which is suggestive of the inconsistent nature of the so-called "MV repair in HCM."

In conclusion, proper and extended left ventricular septal myectomy is associated with elimination of the LVOTO, 
and it is rare, if ever, that the MV needs to be manipulated in the absence of intrinsic MV disease in these cases. However, long-term data on such maneuvers are needed.

\section{References}

1. Salmasi MY, Naqvi D, Pantazis A, Salmasi AA, De Robertis F. Unusual case of combined aortic root replacement and repair of hypertrophic obstructive cardiomyopathy. J Thorac Cardiovasc Surg. 2020;159:e295-7.

2. Said SM, Dearani JA, Ommen SR, Schaff HV. Surgical treatment of hypertrophic cardiomyopathy. Expert Rev Cardiovasc Ther. 2013;11:617-27.
3. Said SM, Schaff HV, Abel MD, Dearani JA. Transapical approach for apical myectomy and relief of midventricular obstruction in hypertrophic cardiomyopathy. J Card Surg. 2012;27:443-8.

4. Said SM, Schaff HV. Surgical treatment of hypertrophic cardiomyopathy. Semin Thorac Cardiovasc Surg. 2013;25:300-9.

5. Hong JH, Schaff HV, Nishimura RA, Abel MD, Dearani JA, Li Z, et al. Mitral regurgitation in patients with hypertrophic obstructive cardiomyopathy: implications for concomitant valve procedures. J Am Coll Cardiol. 2016;68: 1497-504.

6. Holst KA, Hanson KT, Ommen SR, Nishimura RA, Habermann EB, Schaff HV. Septal myectomy in hypertrophic cardiomyopathy: national outcomes of concomitant mitral surgery. Mayo Clin Proc. 2019;94:66-73. 